File 2775, 43(4) 2nd Print (14)

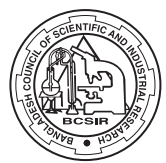

Avaiable online at www.banglajol.info

Bangladesh J. Sci. Ind. Res. 43(4), 559-570, 2008

BCSIR

\begin{tabular}{c}
\hline \hline BANGLADESH JOURNAL \\
OF SCIENTIFIC AND \\
INDUSTRIAL RESEARCH \\
\hline \hline E-mail: bjsir07gmail.com
\end{tabular}

\title{
Studies on Smoke Opacity of Different Type of Diesel Vehicles in Dhaka City
}

\author{
M. A. Rouf ${ }^{*}$, H. H. Hasib ${ }^{b}$, and M. Nasiruddin ${ }^{b}$ \\ ${ }^{a}$ Institute of Fuel Research and Development, BCSIR, Dr. Qudrat-I- Khuda Road, \\ Dhanmondi, Dhaka-1205. ${ }^{b}$ Department of Environment, Ministry of Environment and \\ Forest, Dhaka-1207.Bangladesh.
}

\begin{abstract}
Six hundred and four diesel vehicles were tested for smoke opacity from September 2001 to December 2004 in Dhaka City. Type of diesel vehicles were single decker, double decker, minibus, jeep and microbus, mini truck, human hauler and maxi, pickup and mini covered van, truck and cover van. Tests conducted on mini truck, maxi and human hauler revealed that about $90 \%$ of these vehicles had smoke opacity more than $90 \mathrm{HSU}$ and were not fit to ply on the city roads. The study on pick up and mini cover vans revealed that about $71 \%$ of the vehicles had smoke opacity more than 90 HSU. $60.2 \%$ mini buses showed smoke emission more than 80 HSU. Most of the single decker and double decker buses had smoke opacity within permissible level of $80 \mathrm{HSU}$. No correlation has been found between the age of the vehicles and emission of smoke from them.
\end{abstract}

Keywords: Smoke opacity, Gross polluter, Emission study, Air pollution

\section{Introduction}

Transport scenario of Dhaka is characterized by very heterogeneous mix of motorized and non-motorized vehicles. The vehicle population in the city is estimated about 400,000 motorized vehicles of various makes, models, and country of manufacture and unaccounted number of non-motorized vehicles. Slow moving traffic, long waits at traffic lights, and traffic jams can be generally sighted on the city roads. Chronic conges tion, poorly managed traffic systems and severe air pollution are the manifestations of the inadequacies of urban governance of Dhaka city. Motorized transports are suspected to be the single largest contributor of air pollution in Dhaka, with annual vehicular growth rate of about 7 to $10 \%$ for last ten years (Report on Roadside Vehicle Emission Testing Program in Dhaka, 2006).

* Author for correspondence. 
Since January 2003, the phase-out of two stroke three wheeler baby taxi resulted in significant air quality improvement in Dhaka City. The decrease in the average PM10 (particulate matter, less than 10 micron in diameter) and PM 2.5 (particulate matter, less than 2.5 micron in diameter) levels for the week after the ban were found to be $31 \%$ and $41 \%$ respectively from the week before ban. The decline in the hydrocarbon was even higher than $50 \%$. The decline in CO of about 28\% was measured in AQMP (Air quality Management Project), Department of Environment).

Overall it was estimated that the impact of the ban translated to about $24 \mathrm{mg} / \mathrm{m}^{3}$ decrease in the PM10 in Dhaka on yearly basis. Impact of banning of two-stroke engine of airborne particulate matter concentrations in Dhaka has been studied (Begum et al., 2006).

Begum et al., (2005) also investigated the sources of atmospheric aerosol at a hot spot area in Dhaka, Bangladesh. A high concentration of air pollutants such as black carbon in Dhaka City has been reported (Salam et al., 2003). Vehicular emission, as well as biomass/coal burning for cooking and in the brick kilns around the city, are the main contributor to these emissions (Cheloulakou et al., 1999; Kassomenos et al., 1995). Investigation of sources of atmospheric aerosol at urban and semi-urban areas in Bangladesh has been studied (Begum et al. 2004).
However, the phase-out of baby taxis led to a void in the public transport infrastructure for some time, ensuing in a sudden influx of a large number of polluting vehicles, such as mini buses, maxi and human-haulers. The number of such vehicle has grown significantly since then (including the addition of number of new buses, some of which run CNG), therefore there is not enough road space for all the motor vehicles in the city resulting traffic congestion. It is well documented that such traffic conditions lead to higher emissions from motor vehicles compared to smooth flow of traffic. Recent data from Continuous Air Quality Monitoring Station (CAMS) show that air quality of Dhaka City is worsening, although the city had some gains from the baby taxi phaseout. There is an urgent need to ensure that the growth in vehicular traffic and transport infrastructure in Dhaka is environmentally sound and sustainable. It has become essential to formulate policy option to tackle the problem of gross polluting diesel vehicle, with a view to arresting and possibly reversing the deteriorating trend in air quality.

Diesel engine emissions are now the major source of PM (particulate matter) and therefore significant improvements in air quality will only be realized through diesel engine emission control. Recent emission inventory analysis shows that more than $80 \%$ of $\mathrm{PM}$ pollution in the transport sector comes from diesel vehicle. Particularly, in winter particulate matter remains a major public health 
threat in Dhaka City with concentration level (24h-average) exceeding standards by two and a half times occasionally.

Role of NO in diesel particulate control has been studied (Cooper and Thoss, 1989). Emission reduction and operation experiences with heavy duty diesel fleet vehicles retrofitted with continuously regenerated diesel particulate filters in Southern

California was investigated (Chatterjee et al., 2001). Work on performance characteristics of novel diesel oxidation catalyst has been done (Voss et al., 1994).

Scientists have studied on health effects of diesel vehicle emission. Diesel exhaust is a likely carcinogen that also impairs immune, reproductive and nervous systems. In 1998, the Scientific Review Panel for the California Air Resources Board reviewed diesel exhaust as a toxic air contaminant and set a lifetime unit cancer risk from diesel particles at 3 in 10.000 persons for each microgram of annual average diesel exposure (California Air Resources Board1998). This is equivalent to 300 in a million excess lung cancers. In May 2002, EPA issued its Health Assessment for Diesel Exhaust which found diesel particulate matter to be a "likely" carcinogen, EPA did not settle on a unit risk factor but recommended a lifetime cancer risk range from 1 in 1,000 to 1 in 100,000 EPA (Health Assessment Document for Diesel Exhaust, May 2002) . The California unit risk falls within this range (The Report on Diesel Exhaust as adopted at the Panel's April 22, 1998).

Nevertheless, diesel fuel has the added benefit of low volatility, which virtually eliminates evaporative $\mathrm{HC}$ emissions. Because of their fuel efficiency and greater power, diesel engines have been strongly favored for heavy-duty applications. But in Bangladesh, where the majority of the vehicles are very old and poorly maintained, we do not get these benefits. Moreover, the lack of inspection and maintenance, high sulfur diesel fuel makes the diesel vehicles gross polluters.

Emission standards for buses (including minibuses) and trucks (including jeep, microbuses and other diesel vehicle) are 80 and 90 Hartridge Smoke Unit (HSU) respectively effective from 01 September 2004, it will be tighten time to time (Bangladesh Gazette, July 19, 2005). The emission standards for diesel vehicle are not regulated properly due to lake of synchronize programme of different legislation authority. Up till now Department of Environment has completed some enforcement programme for vehicle emission control with other legislative authority and fined considerable money for gross polluting vehicle. But these efforts were insignificant to control vehicular emission of the mega city.

Although few scientific studies have been done on air quality of Dhaka City, no scientific studies have been done on smoke opac- 
ity of diesel vehicles of Dhaka city. The output of the studies will be helpful for decision maker in order to take strategy for vehicle emission control.

\section{The objectives of the research are:}

1. To measure the emission opacity of different types of diesel vehicle in order to identify the gross polluting diesel vehicle in Dhaka City.

2. To control emission from diesel vehicle to improve air quality of Dhaka city.

3. Create public awareness for proper maintenance of vehicles for reduction of emission to tolerable limit.

\section{Materials and Methods}

The diesel vehicle emission of Dhaka has been studied under the Enforcement Program of AQMP using the following methodology.

A Wager 6500 full flow smoke meter (opacity meter) was used for the measurement of opacity of smokes emitted by the vehicles. The diameter of the vehicle exhaust pipe or of the extension pipe was also recorded against the measured data for each vehicle to convert the data to smoke density in terms of m-1 units or to \% opacity for a common optical path length of $430 \mathrm{~mm}$ as applicable for Hartridge Smoke Units (HSU).

While carrying out smoke measurements using a full flow smoke meter, care was taken that the smoke meter was fixed to the vehicle tail pipe or the extension pipe in such a way that the axis of the smoke meter light beam was perpendicular to the axis of exhaust flow. Further, the centerline of the light beam axis was located as close as possible, but in no case further than $70 \mathrm{~mm}$ from the exhaust outlet.

To ensure proper fixing of the Wager smoke meter to the tail pipe of different test vehicles, extension pipes with different inner diameters (51, 59, and $76 \mathrm{~mm}$ ) suitable for different vehicles were fabricated in such a way that the inner diameter of the extension pipe was equal or slightly larger than the tail pipe diameter of the test vehicle. The length of the extension pipe was more than 10 times the inner diameter of the extension pipe. To properly align the light beam of the smoke meter and to keep always a fixed distance of approximately 35 to $45 \mathrm{~mm}$ between the end of the exhaust pipe and the centerline of light beam axis, a fixture was added to the extension pipe to install the 'sensor head' of the smoke meter.

The parameter measured from diesel engine vehicles was the smoke emission (smoke opacity) under free/snap acceleration test. The free acceleration test does not really represent normal operation conditions. A loaded smoke test is a better representation of smoke emissions in real operation. It has also been observed that smoke opacity par- 
ticularly when measured under free acceleration is not well correlated with particulate emissions especially for modern electronically controlled fuel injection engines or turbocharged engines with boost control (Faiz et al, 1996 and NEPC, 2001). In these advanced technology engine vehicles, the contribution of carbonaceous matter (soot) to the particulate emissions decreases due to improvements in engine combustion and fuel quality. However, smoke is a public nuisance and is harmful to health. High smoke emissions indicate malfunctioning of engine and/or mal-adjustment of engine settings and components.

Again, the loaded smoke tests require chassis dynamometer and other infrastructure facilities. With all its shortcomings, the free acceleration smoke test has been adopted for inspection of the in-service diesel vehicles in a large number of countries. The procedure followed for the measurement of smoke from diesel driven vehicles was by using the free acceleration method.

Six hundred and four diesel vehicles were tested for smoke opacity from September 2001 to December 2004, the breakdown of which is given in Table-I. Due to the restriction of truck movement during day time in the city, smoke test for the trucks were conducted near the truck terminal at Aminbazar, Dhaka.

\section{Analysis of Data}

The smoke data for diesel vehicles were recorded in log sheets from print outs of the smoke meters. Data collected in the field were corrected and converted, where necessary, and entered into an Excel spreadsheet, which was then subsequently organized and analyzed using the SPSS Software. Proposed emission standards were used for the analysis and comparison of the data for the pass and fail.

Table I. Types of diesel vehicles used for analysis

\begin{tabular}{c|c|c}
\hline Sl .No. & Vehicle type & No. of Vehicles \\
\hline 01 & Single decker & 135 \\
02 & Double decker & 142 \\
03 & Mini bus & 98 \\
04 & Jeep and microbus & 42 \\
05 & Mini truck, human hauler and maxi & 38 \\
06 & Pick up and mini covered van & 35 \\
07 & Truck and covered van & 114 \\
\hline
\end{tabular}




\section{Result and Discussion}

\section{Single decker buses}

The graph of frequency of vehicles VS smoke opacity of single decker buses is shown in Fig. I. Smoke opacity value of $46.67 \%$ buses was found to be higher than $80 \mathrm{HSU}$ and remaining $53.33 \%$ buses smoke opacity value lower than 80 HSU. Smoke opacity of 61 TATA single decker buses (out of total 135 buses) was tested. 44.26\% showed opacity less than $80 \mathrm{HSU}$ and remaining $55.74 \%$ showed opacity higher than 80 HSU.

\section{Double decker buses}

83.8\% double decker buses were plying with the opacity less than 80 HSU whereas16.2\% were plying with the opacity higher than 80 HSU. Frequency distribution of double decker buses as shown in Fig 2. Out of 124 Ashoke Leyland double decker buses $66.13 \%$ were opacity value less than $80 \mathrm{HSU}$ and rest $33.87 \%$ operating with opacity higher than 80 HSU. Opacity of 18 Volvo double decker buses (out of total 142 double decker buses) was tested. All the Volvo buses were found smoke opacity less than 50 HSU. Volvo buses were the best among all the

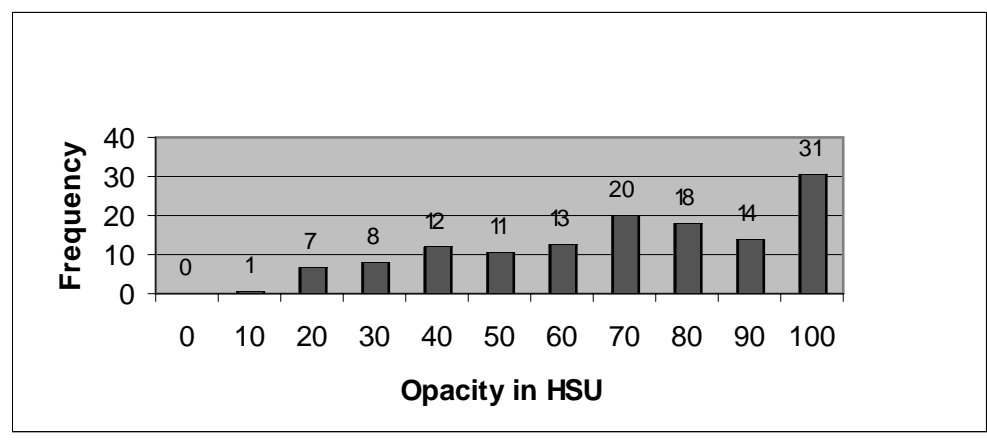

Fig. 1. Frequency distribution for single decker buses.

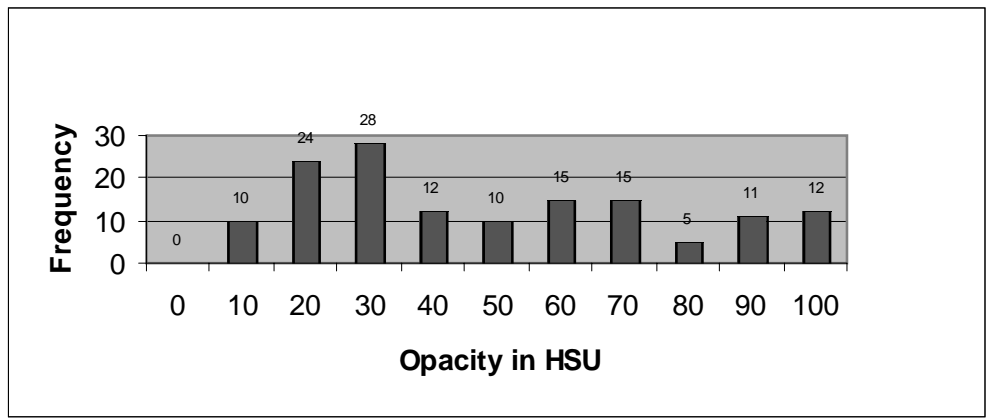

Fig. 2. Frequency distribution for double decker buses 
buses plying in the roads of Dhaka City. Average smoke opacity of Volvo and Ashoke Leyland buses were 34 and 45 HSU respectively. Opacity of Volvo buses were much less than Ashoke Leyland buses. Volvo buses were considered as the most environments friendly.

\section{Mini buses}

$39.8 \%$ mini buses were found to be less than 80 HSU and $60.2 \%$ were found opacity value higher than 80 HSU. Mini buses were considered as serious polluters. The graph of Frequency VS Opacity as shown in Fig. 3.

\section{Jeeps and Micro buses}

Microbuses were examined for smoke opacity as shown in Fig.4. Opacity of 50\% jeeps and microbuses were below $90 \mathrm{HSU}$ and remaining $50 \%$ were found smoke opacity higher than 90 HSU.

\section{Maxi and human Hauler}

The graph of Frequency VS Smoke opacity of maxi and human hauler is as shown in Fig. 5. $10.53 \%$ of maxi, human hauler and mini pick-ups were found to be opacity below 90 HSU and $89.47 \%$ of the vehicles were showed opacity higher than 90 HSU.

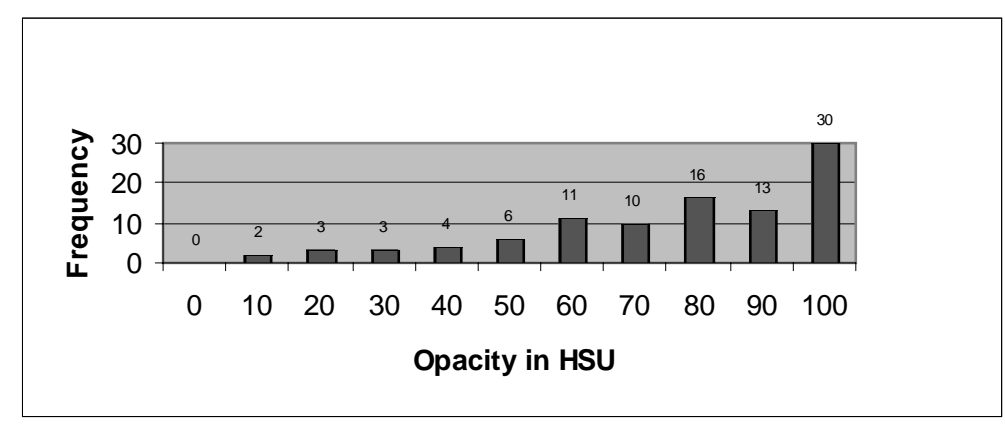

Fig. 3. Frequency distribution for mini buses

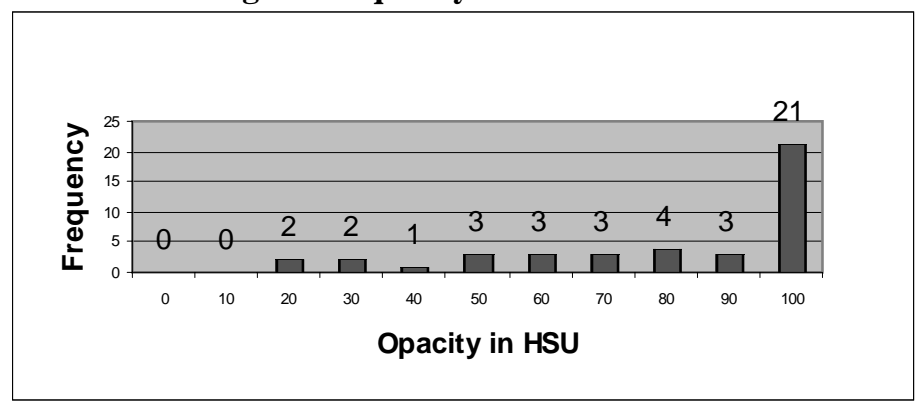

Fig. 4. Frequency distribution for jeep and microbuses 


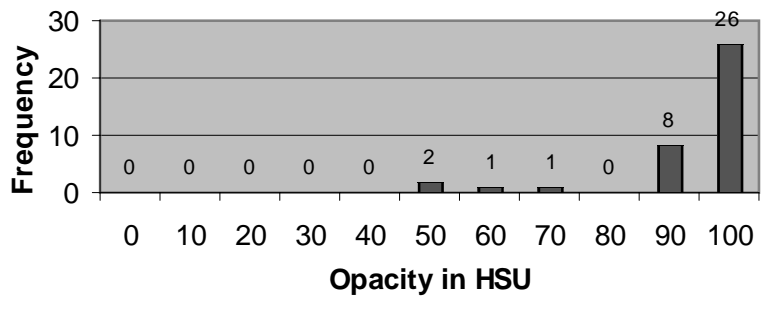

Fig. 5. Frequency distribution for maxi and human haulers

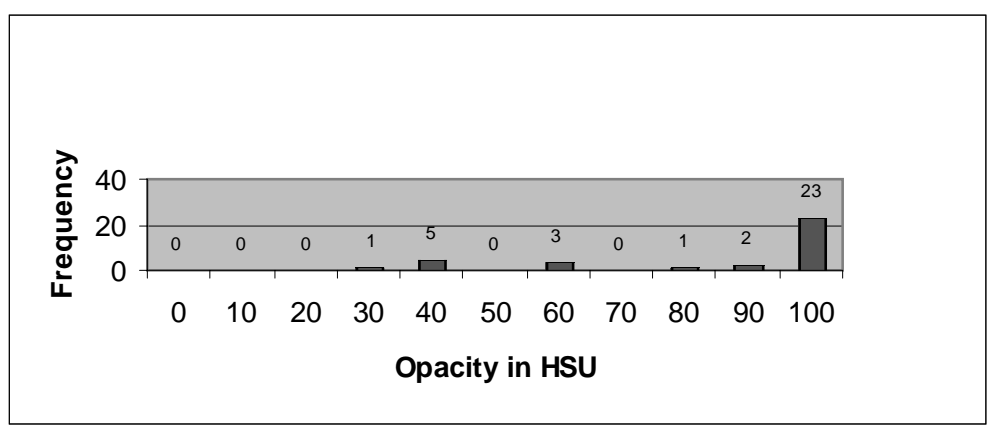

Fig. 6. Frequency distribution for pickup and mini covered van

\section{Pickups and Mini Covered Vans}

Of the 35 pick ups and mini covered vans 28.57\% were showed opacity below $90 \mathrm{HSU}$ and $71.43 \%$ of the pick-ups were showed opacity higher than 90 HSU. The graph of frequency distribution for pickup and mini covered van is shown in Fig. 6.

\section{Truck and Cover Van}

114 trucks and covered vans were tested for smoke opacity as shown in Fig. 7. It was

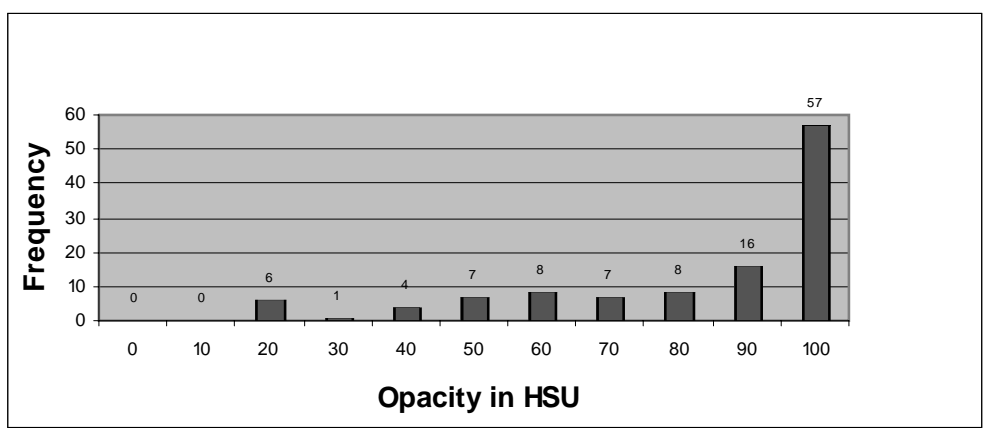

Fig. 7 Frequency distribution for trucks and covered vans 
found that $50 \%$ trucks and covered vans were opacity higher than 90 HSU. Evidently, $50 \%$ of trucks and covered van were plying in very bad condition and polluting air seriously. The average smoke opacity of trucks and cover van was 81 and 66 respectively. Trucks were the worst polluter.

\section{Average smoke opacity of different types of diesel vehicle}

Average smoke opacity of different types of diesel vehicles is as shown in Fig. 8. Maxi and human hauler exhibited maximum average opacity and double decker buses showed minimum average opacity. has been shown that only 235 vehicles were registered out of 604 diesel vehicles that's why realistic smoke opacity from each year did not expose. It has been observed that significant amount of black smoke were emitted each year.

In case of buses, the worst polluters were from the year 1989 (registered time of vehicle) which had greater emission than that of the vehicles from the year 1985 to 1988 . Again, the emission results of 1994 and 2001 were similar. In case of trucks $100 \mathrm{HSU}$ was observed for the trucks made in the year 1974, 1983 and 2001. Evidently, there was

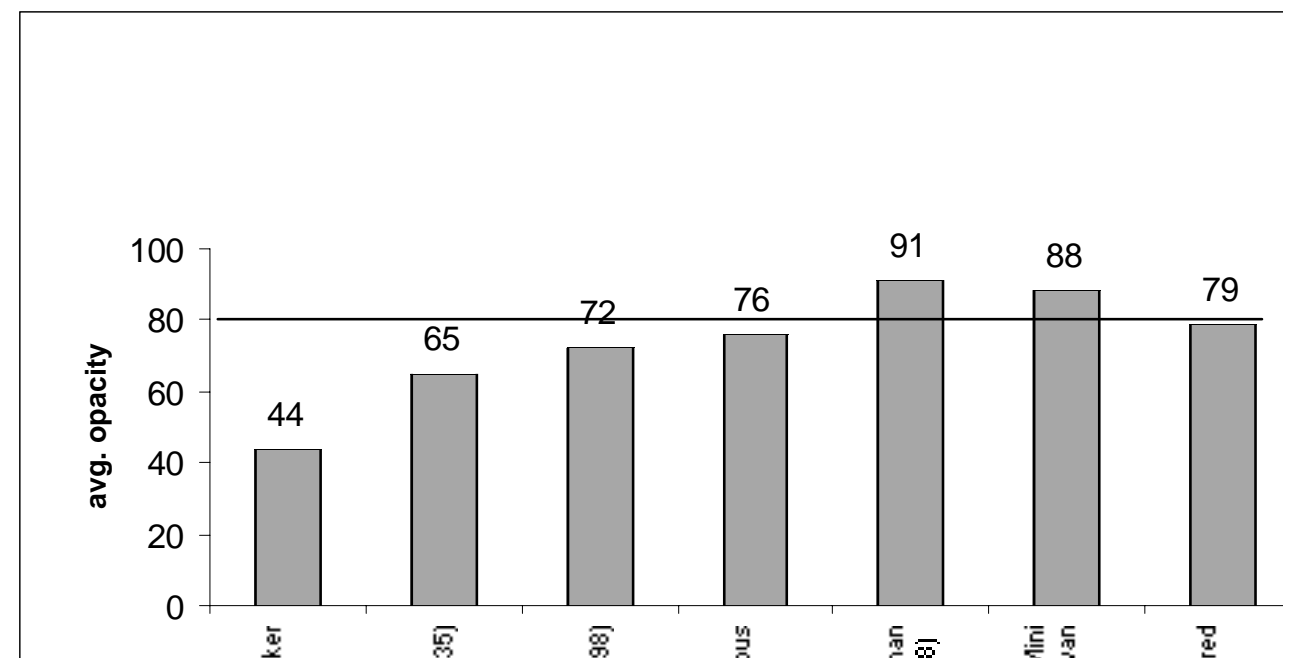

Fig. 8. Comparison of avg. opacity of different types of vehicles

\section{Correlation between Age and emission}

No Clear correlation has been found between the age group of the vehicles and emission characteristics as shown in Fig.9. It no correlation between the age and emission of the fleet of Dhaka. 


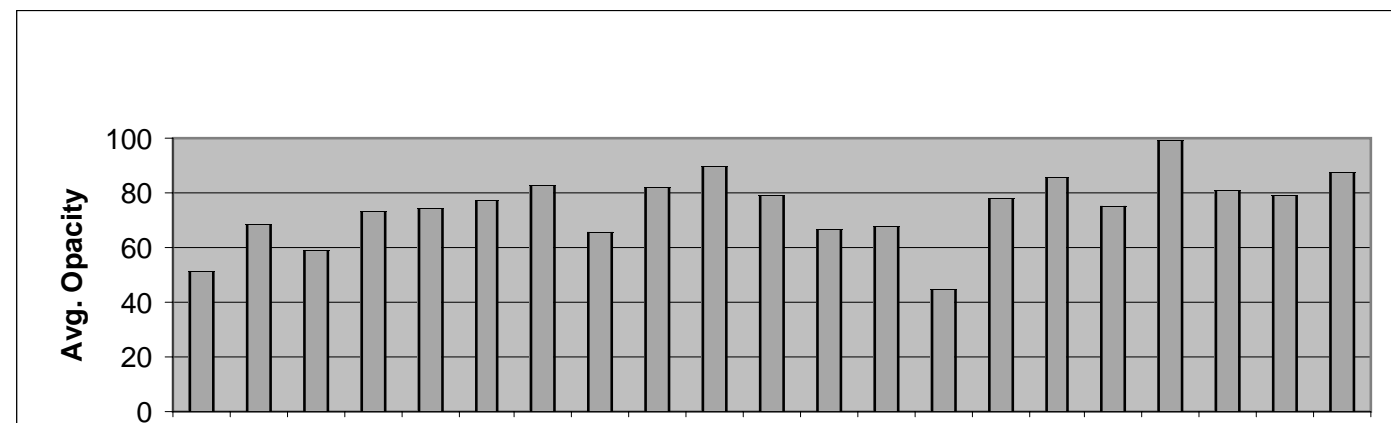

Fig. 9. Avg. smoke opacity as function of vehicle age (235 out of 604)

Table II. Descriptive statistics of the smoke opacity in HSU distribution of different types of vehicles in Dhaka City

\begin{tabular}{|c|c|c|c|c|c|c|c|}
\hline \multirow{2}{*}{$\begin{array}{l}\text { Descriptive } \\
\text { statistics }\end{array}$} & \multicolumn{7}{|c|}{ Smoke opacity (HSU) } \\
\hline & $\begin{array}{l}\text { Single } \\
\text { decker } \\
\text { buses }\end{array}$ & $\begin{array}{c}\text { Double } \\
\text { decker } \\
\text { buse }\end{array}$ & Minibuses & $\begin{array}{c}\text { Jeep and } \\
\text { Microbuses }\end{array}$ & $\begin{array}{c}\text { Maxis and } \\
\text { human } \\
\text { haulers }\end{array}$ & $\begin{array}{c}\text { Pickups } \\
\text { and mini } \\
\text { covered } \\
\text { vans }\end{array}$ & $\begin{array}{c}\text { Trucks } \\
\text { and } \\
\text { covered } \\
\text { vans }\end{array}$ \\
\hline Mean & 65.44 & 44.07 & 71.96 & 76.08 & 91.23 & 88.22 & 78.94 \\
\hline $\begin{array}{l}\text { Standard } \\
\text { error of mean }\end{array}$ & 2.28 & 2.34 & 2.51 & 4.01 & 2.36 & 4.31 & 2.31 \\
\hline Median & 68.25 & 37.37 & 75.33 & 88.94 & 97.77 & 96.38 & 90.23 \\
\hline Mode & 69 & 16 & 88 & $15 a$ & 42 & $23 a$ & $15 a$ \\
\hline Minimum & 9 & 4 & 5 & 15 & 42 & 23 & 15 \\
\hline Maximum & 100 & 100 & 100 & 100 & 100 & 100 & 100 \\
\hline Range & 91 & 96 & 95 & 85 & 58 & 77 & 85 \\
\hline $\begin{array}{l}\text { Standard } \\
\text { deviation }\end{array}$ & 26.53 & 27.84 & 24.82 & 26.02 & 14.55 & 25.52 & 24.67 \\
\hline Variance & 704.03 & 775.09 & 615.86 & 676.84 & 211.81 & 651.35 & 608.49 \\
\hline Kurtosis & -0.944 & -0.911 & 0.007 & 0.061 & 4.557 & 0.141 & 0.153 \\
\hline $\begin{array}{l}\text { Standard } \\
\text { error of kurtosis }\end{array}$ & 0.414 & 0.404 & 0.483 & 0.717 & 0.750 & 0.778 & 0.449 \\
\hline Skew ness & -0.368 & 0.515 & -0.833 & -1.068 & -2.237 & -1.227 & -1.144 \\
\hline $\begin{array}{l}\text { Standard } \\
\text { error of } \\
\text { Skew ness }\end{array}$ & 0.209 & 0.203 & 0.244 & 0.365 & 0.383 & 0.398 & 0.226 \\
\hline Count & 135 & 142 & 98 & 42 & 38 & 35 & 114 \\
\hline
\end{tabular}

a Multiple modes exist. The smallest value is shown 


\section{Conclusion}

From the study on over six hundred vehicles, the smoke opacity data tell us that ninety percent of mini truck, maxi and human haulers are not fit to ply on the city roads, having a staggering smoke emission of over 90 HSU. Not surprisingly, sixty percent of the minibuses do not meet the approved emission standard. Small diesel vehicles like pick up and mini covered vans are also gross polluters: seventy one percent of these vehicles showed smoke emission value more than $80 \mathrm{HSU}$. And an alarming fifty percent microbus and jeeps had smoke opacity more than 90 HSU. Fifty percent of single decker diesel buses do not meet the proposed level of $80 \mathrm{HSU}$, contrasting an average of 45 HSU smoke emission for a double decker Ashok Leyland bus and 34 HSU for a Volvo. Both these vehicles evidently maintained smoke emission level less than 80 HSU.

Therefore with improved vehicle maintenance, reduction of sulfur in diesel in the longer terms, introduction of state-of-the-art diesel engine and advanced emission control system, Bangladesh can have a diesel fleet, which in turn will make our environment cleaner. It is absolutely necessary to work out a plan to address the problem of emission from these vehicles. The studies on smoke opacity of diesel vehicle in Dhaka City will be very useful for decision maker in order to take strategy for vehicle emission control.

\section{Reference}

Air Quality Management Project (AQMP), Department of Environment (DoE), (March 2006). Ministry of Environment and Forest, Government of Bangladesh, Report on Roadside Vehicle Emission Testing Program in Dhaka: Chapter 1, page-1.

Bangladesh Gazette (19th July 2005). Emission standards for in-use diesel vehicle registered before September 1, 2004. Part D, p7571

Begum, B.A. Biswas, S.K. Kim, E. Hopke, P.K. Khaliquzzaman, M. (2005). Investigation of Sources of Atmospheric Aerosol at a Hot Spot Area in Dhaka, Bangladesh; J. Air Waste Manage. Assoc., 55: 227-240.

Begum, B.A. Kim, E. Biswas, S.K. Hopke, P.K. (January 2006). Impact of banning twostroke engine of airborne particulate matter concentrations in Dhaka, Bangladesh. Air and Waste Manage. Association. 56: 85-89

Begum, B.A. Kim, E. Biswas, S.K. Hopke, P.K. (2004). Investigation of Sources of Atmospheric Aerosol at Urban and SemiUrban Areas in Bangladesh; Atmos. Environ., 38: 3025-3038.

California Air Resources Board (1998). Resolution 98-35. Identification of diesel exhaust as a toxic air contaminant. 
Chatterjee, S. McDonald, C. Conway, R. Windawi, H. Vertin, K. LeTavec, C. Gautam, M. Clark, N. (2001). Emission reductions and Operational Experiences with Heavy Duty Diesel Fleet Vehicles Retrofitted with Continuously Regenerated Diesel Particulate Filters in Southern California. SAE Technical Paper 2001-010512.

Cheloulakou A Assimacopoulos D Lekkas T.Foredasting (1999). Daily maximum O3 concentrations in the Atherns Basin. Environ Monit Assess; 56: 2559-67.

Cooper, B. Thoss, J. (1989). Role of NO in Diesel Particulate Control, SAE Technical Paper 890404.

EPA, Health Assessment Document for Diesel Exhaust (May 2002). Office of Research and Development, EPA/600/8-90/057F at: http://cfpub.epa.gov/ncea/cfm/recordisplay.cfm?deid=29060.

Faiz, A. Weaver, C.S. Walsh, M.P. (1996). Air Pollution from Motor Vehicles: Standards and Technologies for Controlling Emissions, The World Bank, Washington, D.C.
Findings of the California Air resources Board's Scientific Review Panel on The Report on Diesel Exhaust as adopted at the Panel's April 22, 1998, meeting. http://www. arb.ca.gov/toxics /dieseltac/ de-fnds.pdf.

Kassomenos, P. Kotroni, V. Kallos, G. (1995). Analysis of climatological and air quality observations from greater Athens area. Atmos Environ 29B: 3671-88.

National Environment Protection Council (NEPC), (2001). Proposed Diesel Vehicle Emissions National Environment Protection Measure Preparatory Work, Inservice Emissions Testing-Pilot Study, Fault Identification and Effect of Maintenance.

Salam, A. Bauer, H. Kassin, K. Ullah, SM. Puxbaum, H. (2003). Aerosol chemical characteristics of a mega-city in Southeast Asia (Dhaka, Bangladesh). Atmos Environ; 37: 2517-28.

Voss, K. Yavuz, B. Hirt, C. Farrauto, R. (1994.) Performance Characteristics of a Novel Diesel Oxidation Catalyst, SAE Technical Paper 940239, 1994.

Received : May, 04, 2008;

Accepted : August 13, 2008 